\title{
Revisiting radiation therapy for esophageal cancer
}

\author{
Hideaki Shimada ${ }^{1}$
}

Received: 31 January 2020 / Published online: 20 February 2020

(C) The Japan Esophageal Society 2020

Despite improvements in diagnostic tools and surgical techniques, many patients with esophageal carcinoma still suffer from early recurrence and poor prognosis. Radiation with chemotherapy and/or molecular therapy may be advantageous in prolonging patient survival. After a long history of research on radiation therapy, essential local controls have been reported based on real-world data. In this volume, Nemoto et al. compared clinical responses following $50.4 \mathrm{~Gy}$ in 28 fractions and $60 \mathrm{~Gy}$ in 30 fractions as a definite radiation dose based on the Comprehensive Registry of Esophageal Cancer in Japan [1]. They concluded that outcomes following $50.4 \mathrm{~Gy}$ in 28 fractions were not inferior to those following $60 \mathrm{~Gy}$ in 30 fractions. Although such evidence was not new to the world, it had sufficient impact on Japanese clinicians. Moreover, some patients in the 50.8 Gy group showed a better survival than those in the $60 \mathrm{~Gy}$ group, partly owing to the frequency of other causes of death; however, the difference was not significant.

Hashimoto et al. reported good clinical response following "induction" radiation with docetaxel, cisplatin, and 5-fluorouracil for potentially unresectable esophageal cancer [2]. Similar to previous reports, they confirmed high pathological complete response rate but relatively high postoperative complication rates. Among the gastroenterological cancer treatment strategies, neoadjuvant therapy will become considerably more popular than before [3]. With the addition of biomarker selection [4], response rates and prognosis may improve compared with those reported previously. Katada et al. reported good clinical outcomes in seven patients with resectable small cell neuroendocrine carcinoma of the esophagus via definitive chemoradiotherapy. Because small cell carcinoma of the esophagus is a rare histological subtype, standard treatment strategies for esophageal small cell carcinoma usually follow those of lung small cell carcinoma.

Hideaki Shimada

hideaki.shimada@med.toho-u.ac.jp

1 Department of Gastroenterological Surgery and Clinical Oncology, Toho University Graduate School of Medicine, Tokyo, Japan
Accordingly, Katada et al. showed $100 \%$ complete response with a median survival time of 32 months [5].

The overall trend in the development of new modalities for advanced esophageal carcinoma seems to be limited in molecular therapy. However, a revisitation on radiation therapy has shown good improvements in patient condition and survival.

\section{Compliance with ethical standards}

Conflict of interest The author declares that he has no conflict of interest.

\section{References}

1. Nemoto K. Comparison of the effects of radiotherapy doses of $50.4 \mathrm{~Gy}$ and $60 \mathrm{~Gy}$ on outcomes of chemoradiotherapy for thoracic esophageal cancer: subgroup analysis based on the Comprehensive Registry of Esophageal Cancer in Japan from 2009 to 2011 by the Japan Esophageal Society. Ann Gastroenterol Surg. 2020. https://doi.org/10.1007/s10388-019-00711-x.

2. Shirakawa Y. Induction chemoradiotherapy including docetaxel cisplatin, and 5-fluorouracil for locally advanced esophageal cancer. Ann Gastroenterol Surg. 2020. https://doi.org/10.1007/s1038 8-019-00709-5.

3. Shimada H. Recent standpoints on preoperative treatment of gastroenterological cancers: who will be a real beneficiary? Ann Gastroenterol Surg. 2019;3:580. https://doi.org/10.1002/ags3.12293.

4. Shimada H. p53 molecular approach to diagnosis and treatment of esophageal squamous cell carcinoma. Ann Gastroenterol Surg. 2018;2:266-73. https://doi.org/10.1002/ags3.12179.

5. Katada C, et al. A retrospective study of definitive chemoradiotherapy in patients with resectable small cell neuroendocrine carcinoma of the esophagus. Ann Gastroenterol Surg. 2020. https:// doi.org/10.1007/s10388-019-00686-9.

Publisher's Note Springer Nature remains neutral with regard to jurisdictional claims in published maps and institutional affiliations. 